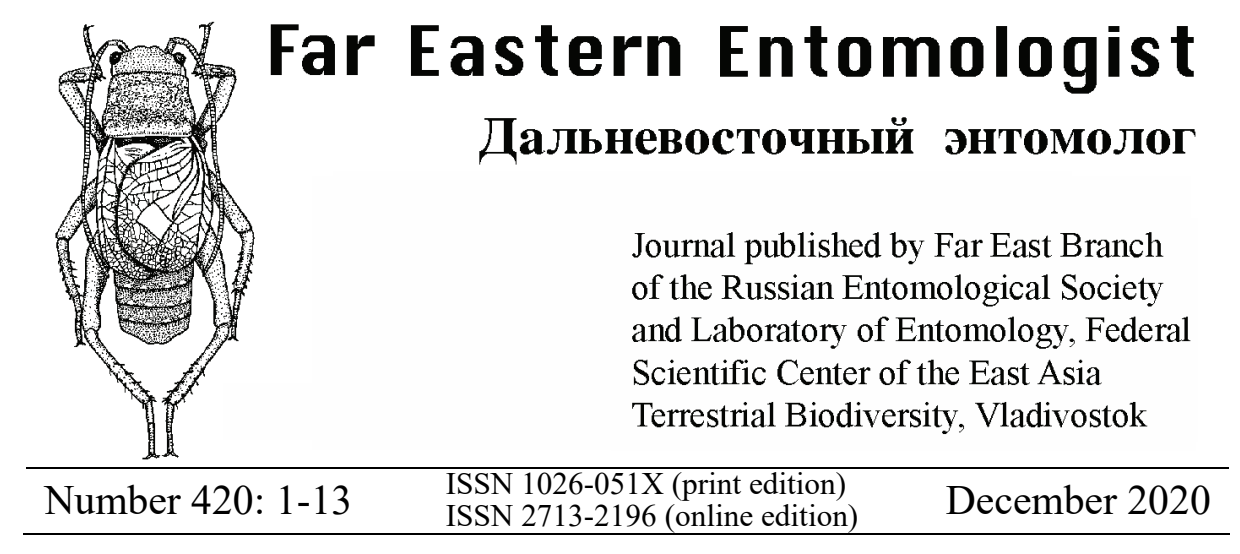

https://doi.org/10.25221/fee.420.1

http://zoobank.org/References/F8FBF14B-6855-47F5-A997-C2EF7933CF45

\title{
NEW CONTRIBUTION INTO CONCEPT OF THE TRIBE DEVENILIINI (LEPIDOPTERA: GEOMETRIDAE, ENNOMINAE) BASED ON SKELETON-MUSCULAR ANATOMY OF THE MALE GENITALIA
}

\section{E. A. Beljaev}

Federal Scientific Center of the East Asia Terrestrial Biodiversity Far Eastern Branch of the Russian Academy of Sciences, Vladivostok, 690022, Russia. E-mail: beljaev@biosoil.ru

Summary. Skeleton-muscular anatomy of the male genitalia of Devenilia corearia (Leech, 1891), Synegia ichinosawana (Matsumura, 1925), Platycerota incertaria (Leech, 1891), Lomographa bimaculata (Fabricius, 1775), and Cabera pusaria (Linnaeus, 1758) is described. Probable synapomorphies of Deveniliini, its generic composition and relations to Baptini and Caberini are discussed. Presumably, Deveniliini is separate lineage of ennomies, basal to Baptini and Caberini.

Key words: geometrid moth, Geometridae, Ennominae, Deveniliini, Baptini, Caberini, skeleton-muscular anatomy, phylogeny.

Е. А. Беляев. Новый вклад в концепцию трибы Deveniliini (Lepidoptera: Geometridae, Ennominae) на основе скелетно-мышечной анатомии гениталий самцов // Дальневосточный энтомолог. 2020. N 420. С. 1-13.

Резюме. Описана скелетно-мышечная анатомия гениталий самцов Devenilia corearia (Leech, 1891), Synegia ichinosawana (Matsumura, 1925), Platycerota incertaria (Leech, 1891), Lomographa bimaculata (Fabricius, 1775) и Cabera 
pusaria (Linnaeus,1758). Обсуждаются возможные синапоморфии трибы Deveniliini, еe родовой состав и отношения с Baptini и Caberini. Предположительно, Deveniliini являются отдельной ветвью энномин, базальной для Baptini и Caberini.

\section{INTRODUCTION}

Tribe Deveniliini was established based on the unique features in the male genitalia musculature of the enigmatic East Asian species, the Devenilia corearia (Leech, 1891), the type and single member of the genus Devenilia Wehrli, 1937 (Beljaev, 1998). Two other genera, Synegia Guenée, 1857 and Crypsicometa Warren, 1894 (currently treating as synonym of Platycerota Hampson, 1893), were associated with Deveniliini by similarities in the male and female genitalia skeleton, without the musculature examination (Beljaev, 1998, 2016; Beljaev \& Mironov, 2019). However, most other authors keep Synegia and Crypsicometa in Baptini, following the Holloway's (1994) proposition. Viidalepp (1996) assigned the genus Devenilia to Ennomini, both Synegia and Platycerota (as Crypsicometa) to Caberini, but included Baptini in Caberini. This paper presents and discusses the results of the male genitalia musculature examination of the Synegia ichinosawana (Matsumura, 1925) and Platycerota incertaria (Leech, 1891), in comparison with Lomographa bimaculata (Fabricius, 1775), the type species of Lomographa Hübner, [1825], the type genus of type genus of Baptini, and Cabera pusaria (Linnaeus, 1758), the type species of Cabera Treitschke, 1825, the type genus of Caberini.

\section{MATERIAL AND METHODS}

Material was collected by author in the Russian Far East. The musculature of the male genitalia was studied using the classic technique (Kuznetzov \& Stekolnikov, 2001). The genitalia of moths, fixed in 75-96\% ethanol, were dissected manually under the control of a binocular microscope. The results were photographed with a camera mounted on the microscope and documented using a projector drawing tube. Then, a figure was made partly by hand drawing, partly with using Adobe $\mathbb{R}$ Photoshop ${ }^{\mathrm{TM}}$ software.

The nomenclature of the male genital sclerites and muscles follows Kuznetzov \& Stekolnikov (2001), with some additions by Beljaev (2008). Designations of the male genitalia muscles are given according to the Speidel et al. (1996) proposal, where the first number after the " $m$ " is given according to Forbes (1939), and the second number in brackets is given according to Kuznetzov \& Stekolnikov (1973), when the numbers by both authors are different.

For the discussion, the male genitalia of Devenilia corearia are redescribed here, mainly following the Beljaev (1998) with some changes.

\section{RESULTS}

Devenilia corearia (Leech, 1891)

Figs 1, 2

Devenilia corearia: Beljaev, 1998: 438, fig. 1 
MATERIAL. Russia: Primorskii krai: Pogranichnyi distr., Barabash-Levada, $44^{\circ} 45^{\prime} \mathrm{N}, 131^{\circ} 25^{\prime} \mathrm{E}, 19,28$.VII 1989, 20, E.A. Beljaev leg; $20 \mathrm{~km}$ SE Ussuriisk, Gornotayozhnoe, $43^{\circ} 42^{\prime} \mathrm{N}, 132^{\circ} 09^{\prime} \mathrm{E}, 8$.VII 1990, $2{ }^{\curvearrowright}$, E.A. Beljaev leg.

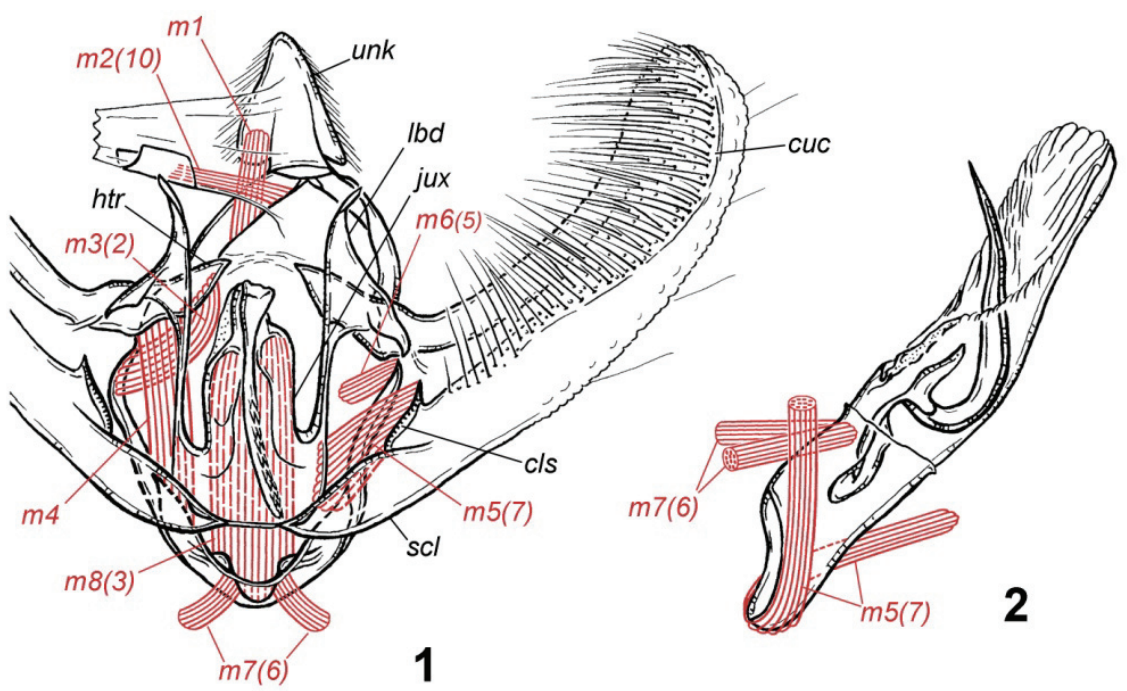

Figs 1, 2. Devenilia corearia (Leech, 1891), musculature of the male genitala. 1 - the male genitalia, ventroposterior view, muscles $m 1, m 2(10), m 3(2), m 4$ are not shown on the right, and muscles $m 5(7), m 6(5)$ are not shown on the left; 2 - phallus, lateral view. Abbreviations: b.pr.v - basal process of valvae, $c l$ - cuiller, $c l p$ - clasper, $c r s$ - cristae, $c s t-$ costa, $c u c$ - cucculus, d.p.unc - distal process of uncus, gn - gnathos, $h t r$ - hemitranstilla, jux juxta, $l b d$ - labidum, m.d.cst - medial dilation of costa, $m 1$ - depressors of uncus, $m 2(10)$ retractors of anal tube, $m 3(2)$ - abductors of valvae, $m 4$ - adductors of valvae, $m 5(7)$, $m 5 a(7 a), m 5 b(7 b)$ - flexors of valvae, $m 6(5)$ - retractors of phallus, $m 7(6)$ - protractors of phallus, $m 8(3)$ - ventral adductors of valvae, $s c l$ - sacculus, teg - tegumen, $t r$ - transtilla, unc uncus, $v n c-$ vinculum.

MALE GENITALIA (Figs 1, 2). The skeleton. Genital segment (annulus) is clearly divided on tegumen and vinculum by thin narrowing. Lateral lobes of tegumen are narrow, ribbon-like, dorsally connected to each other by very small, almost point-like, bridge. Vinculum is wide, strongly sclerotized, lateroventrally with a pair of deep notches. Uncus is wide, triangular, weakly sclerotized dorsally, completely membranous ventrally. Gnathos is lacking. Valvae are long, narrow, with large cucullus, densely covered with long hair-like bristles. Costa is wide, well sclerotized, medially protruded into wide bar-like hemitranstilla angled to apex; apexes of right and left hemitranstillae are widely separated. Valvula proximally is bordered by firm oblique rib - clasper (sensu Beljaev, 2008). Sacculus is relatively short, well sclerotized. Juxta very large, wide, long, distally somewhat asymmetric and extending into a long, thin process movably articulated with the juxta and covered 
with spines on the dorsal side. Pair of very large triangular lateral processes of anellus (labides sensu Beljaev, 2008) are connected medioventrally to laterobasal sides of juxta, and laterally loosely articulated with base of costa. Aedeagus is large, cylindrical, moderately sclerotized, vesica with a single very large subulate cornutus, hook-like at the base.

The musculature. Depressors of the uncus, $m 1$, are thin, weak, extending from the middle part of the anterior edge of the tegumen, distally attached to the lateral corners of the uncus. Anal cone retractors, $m 2(10)$, are extending from most dorsal portion of anterior rib of lateral lobes of tegumen. Dorsal abductors of valvae, $m 3(2)$, are relatively wide, extending from the most dorsal portion of the vinculum, and are attached in distal half of the hemitranstilla to small round dilation of its ventral margin.

Adductors of valvae, $m 4$, are wide, long, extending from a small extension on the ventral part of lateral branches of the vinculum to the ventral edge of the basal half of the hemitranstilla. Flexors of valvae, $m 5(7)$, are short, moderately wide, proximally attached partly to medial wall of the sacculus, partly to lateral edge of the ventral half of the juxta, distally attached to clasper. Ventral extensor of valva, $m 8(3)$, is unpaired, extremely powerful, long and wide, extending proximally from ventral part of the vinculum between its paired notches, distally extending to the articulation of juxta and its distal process, without attaching to the latter. Protractors of phallus, $m 6(5)$, are paired, relatively thin, extending from dorsal corners of vinculum and distally attached to anterior deletion of aedeagus (saccus), but directed differently: right muscle is oriented topologically posterioventrad from saccus, and left muscle is oriented posteriodorsad from saccus. Retractors of the phallus, $m 7(6)$, paired, relatively thin, extending from most ventral posterior edge of vinculum and distally attached to topologically dorsal wall of aedeagus. These unusual features of the muscles attachment are connected with unusual position of the phallus "lying on the side", i.e. turned 90 degree right from common phallus position in ennomines. Retractor of vesica, $m 21$, is present, but not shown.

\section{Platycerota incertaria (Leech, 1891)}

Figs 3, 4

MATERIAL. Russia: Sakhalin, Yasnomorskoe vicinity, N slope of Sokhonda mountain, 46 $44^{\prime} 52 " \mathrm{~N}, 141^{\circ} 55^{\prime} 01^{\prime \prime}$ E, $70 \mathrm{~m}$ asl, 21-23.VII 2019, 20, E.A. Beljaev leg.

MALE GENITALIA (Figs 3, 4). The skeleton. Genital segment is clearly divided on tegumen and vinculum by thin narrowing. Lateral lobes of tegumen are narrow, ribbon-like, dorsally connected to each other by very small, almost point-like, bridge. Vinculum is wide, strongly sclerotized, laterally with a pair deeply invaginated ribs, ventrally broad, lobe-like, subdivided posteriorly by long narrow split. Uncus is strong, L-shaped curved, with semisclerotized socii laterally. Gnathos is vestigial, represented by a pair of small thin bars laterad of the uncus base. Valvae are long, narrow, dorsally connected with vinculum by strong articulation formed by posterior 

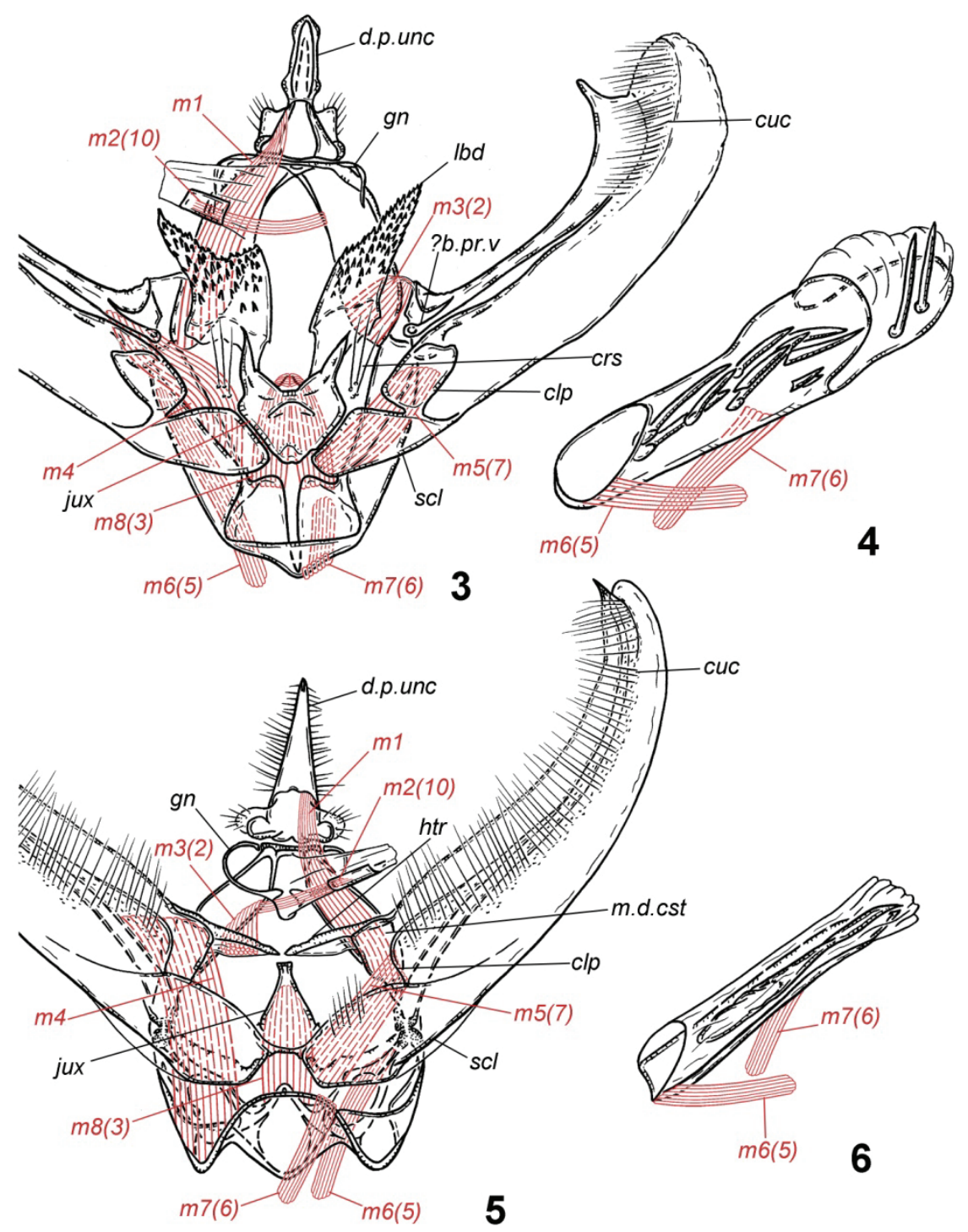

Figs 3-6. Musculature of the male genitala. 3, 4-Platycerota incertaria (Leech, 1891): 3 the male genitalia, ventroposterior view, muscles $m 1, m 4, m 6(5)$ are not shown on the right, and muscles $m 2(10), m 3(2), m 5(7), m 7(6)$ are not shown on the left; 4 - phallus, dorsolateral view, muscles $m 6(5)$ and $m 7(6)$ are not shown on the right. 5, 6-Synegia ichinosawana (Matsumura, 1925): 5 - the male genitalia, ventroposterior view, muscles $m 2(10), m 3(2), m 4$ are not shown on the right, and muscles $m 1, m 5(7), m 6(5), m 7(6)$ are not shown on the left; 6 - phallus, dorsolateral view, muscles $m 6(5)$ and $m 7(6)$ - are not shown on the right. Abbreviations: see Fig. 1. 
dilation of vinculum and anterior thickening of lateral wall of the costa valvae. Costa is wide, well sclerotized, distally somewhat dilated and bearing apical finger-like process, medially with hemitranstilla lacking, but with short and narrow medioventral spring, separated from costa by narrow split. Cucullus spreads along the costa, weakly delimited from valvula. Clasper is a trapezoidal sclerotized plate. Sacculus is relatively short, well sclerotized. Juxta is strong, wide but short, roughly pentagonal, with flattened conic medial invagination, dorsolaterally connected with a pair of enormous labides. The labides are heavy sclerotized, irregular quadrangle, flat, spinose sclerites, laterally loosely connected to the base of costa valvae. Aedeagus is large, sclerotized, cylindrical at basal half and dilated jaws-like distally, vesica is armed with a number firm needle-like cornuti.

The musculature. Depressors of the uncus, $m l$, are moderate, extending from ventral corners of tegumen, distally attached to the lateral sides of uncus at the base of its distal process. Anal cone retractors, $m 2(10)$, are extending from anterior rib of lateral lobes of tegumen remote from their dorsal connection. Dorsal abductors of valvae, $m 3(2)$, are strong but short, extending from the most ventral portion of tegumen to membranous thickening between the valva costa and ventrolateral corner of the labium. Adductors of valvae, $m 4$, are strong, wide and long, extending ventrally from lateral invaginated ribs of vinculum to medioventral spring of costa. Probably, this spring is vestigial basal process of valvae, which in many Ennominae forms ventral protrusion of hemitransilla serves as an apodema for $m 4$. Flexors of valvae, $m 5(7)$, are short, moderately wide, proximally attached to the basal corner of sacculus, distally extending to median aria of medial plate of clasper. Ventral extensor of valva, $m 8(3)$, is paired, powerful, extending proximally from posterior ridges of ventral lobes of the vinculum, distally attaching to the median invagination of juxta. Protractors and retractors of the phallus, $m 6(5)$ and $m 7(6)$, are paired, relatively thin, first ones extending from near the dorsal corners of vinculum and distally attached to lateral sides of anterior opening of aedeagus, and second ones extending from anterior top of saccus to the middle of ventral side of aedeagus. Retractor of vesica, $m 21$, is present, but not shown.

NOTE. Stüning (2000) synonymised Crypsicometa with Platycerota, referring the Holloway's (1994) suggestion on their synonymy. $P$. incertaria, the type species of Crypsicometa, differs from other Platycerota by the present of tremendous labides, but in other structures of the male genitalia it well conforms to the latter. Thus, the male genitalia musculature of $P$. incertaria can presents its pattern in the genus.

\section{Synegia ichinosawana (Matsumura, 1925)}

Figs 5, 6

MATERIAL. Russia: Sakhalin, Yasnomorskoe vicinity, N slope of Sokhonda

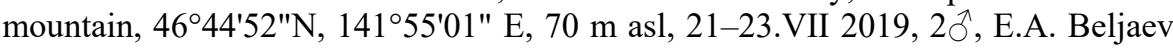
leg.

MALE GENITALIA (Figs 5, 6). The skeleton. Genital segment is clearly divided on tegumen and vinculum by thin narrowing. Lateral lobes of tegumen are narrow, 
ribbon-like, dorsally distanced and connected by extended bar-like bridge. Vinculum is very wide, strongly sclerotized, with complicate internal system of stiffening. Uncus is large, conic, but moderately sclerotized, socii membranous. Gnathos is weak, in form of thin semiring with a pair of lobe-like dilations medioventrally. Valvae are long, narrow, dorsally connected with vinculum by strong articulation formed by posterior dilation of vinculum and anterior thickening of lateral wall of the costa valvae. Costa is very wide, well sclerotized, finished by pointed spine. Hemitranstilla in form of firm and long digital process, left and right hemitranstillae are touching medially. Ventrad of hemitranstilla, costa extends in broad lobe-like medial dilation. Cucullus broadly spreads along the costa almost to clasper, weakly delimited from valvula. Clasper is an arched narrow thickening of proximal edge of valvula. Sacculus is relatively short, well sclerotized, somewhat inflated. Juxta is simple, moderate in size, conic. Labides are lacking. Aedeagus is relatively small, groove-like, membranous dorsally, vesica with a single strong straight subulate cornutus.

The musculature. Depressors of the uncus, $m l$, are moderate, extending from ventral corners of tegumen, distally attached to the anterior margin of the ventral wall of distal process of uncus. Anal cone retractors, $m 2(10)$, are extending from anterior rib of lateral lobes of tegumen remote from their dorsal connection. Dorsal abductors of valvae, $m 3(2)$, are strong and long, extending from the dorsal portion of anterior rib of lateral lobes of tegumen to membranous thickening ventad to distal half of hemitranstilla. Adductors of valvae, $m 4$, are very strong, wide and long, extending ventrally from deep lateroanterior invaginations of vinculum to medial deletion of costa. Judging by the topology and attachment of the $m 4$, this dilation should be a modified ventrobasal portion of hemitranstilla. Flexors of valvae, $m 5(7)$, are short, moderately wide, proximally attached to the basal corner of sacculus, distally extending to clasper. Ventral extensor of valva, $m 8(3)$, is unpaired, powerful, extending proximally from dorsal protrusion on saccus, distally attaching to near the top of juxta. Protractors and retractors of the phallus, $m 6(5)$ and $m 7(6)$, are paired, thin, first ones extending from near the dorsal corners of vinculum and distally attached to lateral sides of anterior opening of aedeagus, and second ones extending from ventolateral sides of posterior rib of vinculum to the middle of ventral side of aedeagus. Retractor of vesica, $m 21$, is present, but not shown.

NOTE. In the male genitalia skeleton, S. ichinosawana differs from Synegia botydaria Guenée, 1857, the type species of the genus Synegia, by absence of a process near the base of costa, and presence single cornutus on vesica instead of two (see Holloway, 1994). But other structures conform well, so the male genitalia musculature of $S$. ichinosawana can presents its pattern in the genus.

Lomographa bimaculata (Fabricius, 1775)

Figs 7-9

MATERIAL. Russia: Primorskii krai, 20km SE Ussuriisk, Gornotayozhnoe,

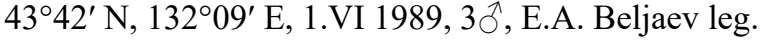




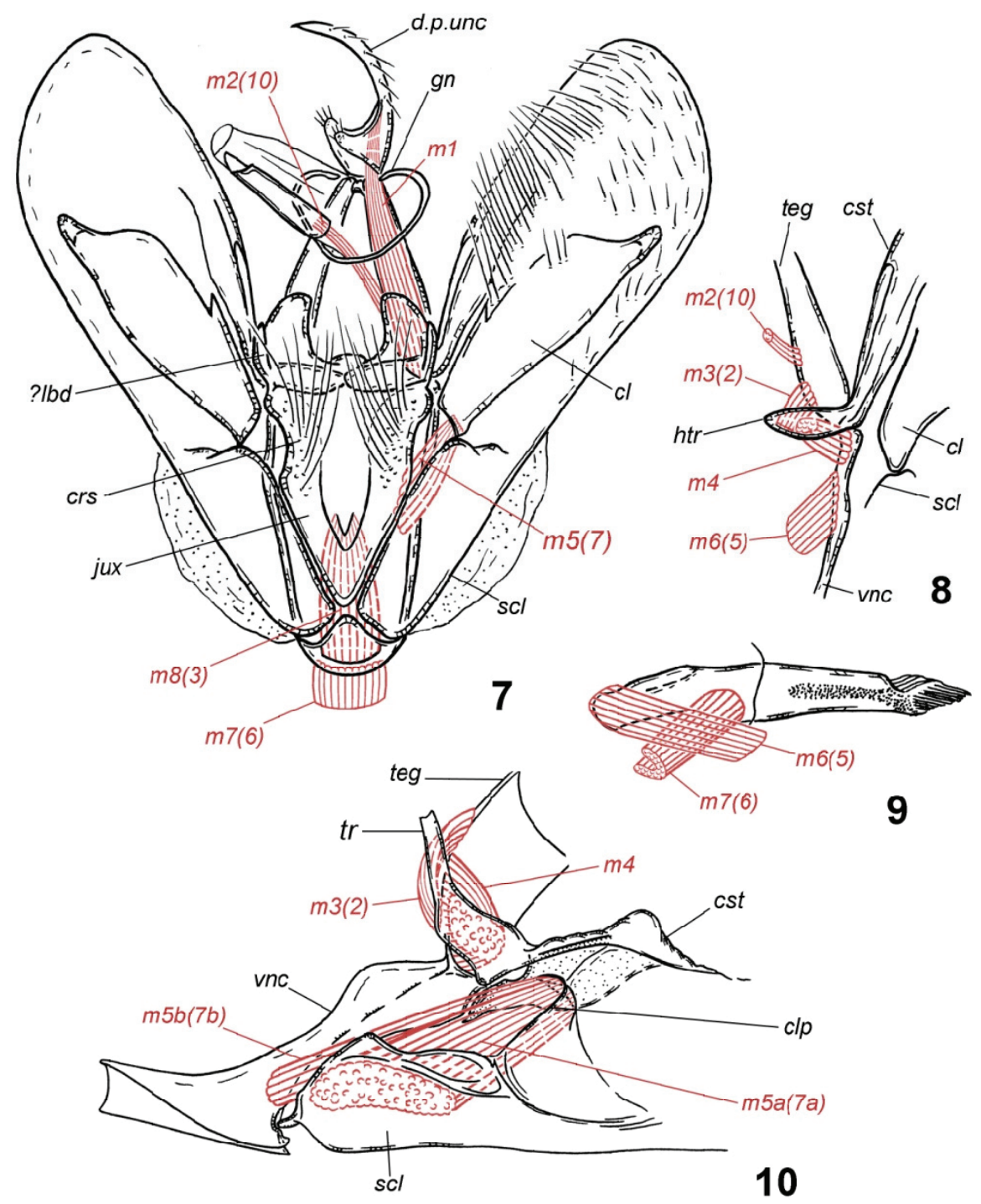

Figs 7-10. Musculature of the male genitala. 7-9 - Lomographa bimaculata (Fabricius, 1775): 7 - the male genitalia, ventroposterior view, muscles $m 3(2), m 4$ and $m 6(5)$ are not shown on the right, and all paired muscles are not shown on the left; 8 - area of tegumen, vinculum and valva articulation, ventroposterior view, muscles $m 5(7)$ are not shown; 9 phallus, lateral view, muscles $m 6(5)$ and $m 7(6)$ are not shown on the right; 10 - Cabera pusaria (Linnaeus, 1758), area of tegumen, vinculum and valva articulation, medial view, muscles $m 1, m 6(5), m 7(6), m 8(3)$ are not shown. Abbreviations: see Fig. 1. 
MALE GENITALIA (Figs 7-9). The skeleton. Genital segment is clearly divided on tegumen and vinculum by thin narrowing. Lateral lobes of tegumen are narrow, ribbon-like, dorsally connected by short bar-like bridge. Vinculum is thin, saccus is not developed. Uncus is thin, long, falcate, socii are large, membranous. Gnathos is weak, in form of thin semiring. Valvae are long and wide, lobe-like, with broad weakly defined cucullus. Costa is moderately sclerotized, wide, in basal half with long longitudinal opening dorsally. Hemitranstilla in form of bar-like lobe with almost parallel sides; left and right hemitranstillae are touching medially. Cuiller (sensu Beljaev, 2008: by origin it is a distal sclerite of sacculus, which in many geometrids remains as a more or less broad plate in the ventrobasal portion of valvula) elongate, large, occupies most of medial side of valvula, distally finished with lobe-like free distal process. Clasper is integrated with cuiller and do not expressed morphologically. Sacculus is long, flat, moderately sclerotized. Juxta is large, broad and long, dorsally with two large lobe-like protuberances, cristae integrated in lateral sides of juxta. Labides are lacking or integrated with juxta in form of two small digital processes located just laterad of the dorsal protuberances. Aedeagus is relatively small, cylindrical, with prominence caecum, vesica bears brush-like group of needle cornuti protruded from the aedeagus.

The musculature. Depressors of the uncus, $m l$, are moderate, extending from ventral corners of tegumen, distally attached to the ventral ribs of lateral sides of uncus just before the base of distal process of uncus. Anal cone retractors, m2(10), are extending from anterior portion of lateral lobes of tegumen. Dorsal abductors of valvae, $m 3(2)$, are short, extending from the anterior rib of tegumen near its ventral corner to ventral margin of distal half of hemitranstilla. Adductors of valvae, $m 4$, are also short, extending from small dilation of dorsal corners of vinculum to the lateral side of basal half of the hemitranstilla. Flexors of valvae, $m 5(7)$, are short, moderately wide, proximally attached partly to the medial wall of the sacculus, partly to the lateral edge of juxta, distally attached to ventral half of proximal rib of cuiller. Ventral extensor of valva, $m 8(3)$, is unpaired, wide, extending from the most ventral portion of vinculum to near the $1 / 3$ length of juxta. Protractors of the phallus, $m 6(5)$, are thin, extending from near the dorsal corners of vinculum just ventrad of $m 4$. Retractor of the phallus, $m 7(6)$, unpaired, wide, extending from ventroanterior rib of vinculum to near the $1 / 3$ length of ventral side of aedeagus. Retractor of vesica, $m 21$, is present, but not shown.

\section{Cabera pusaria (Linnaeus, 1758)}

Fig. 10

Cabera pusaria: Stekolnikov \& Kuznetzov, 1982: 350, fig. 4 B.

MATERIAL. Russia: Primorskii krai, Chuguevsky district, $10 \mathrm{~km}$ SE of Yasnoye, Klyuch Bereznyaki, 550 m asl, 4338'32" N, 13404'22" E, 03.VIII 1995, $2 \hat{\jmath}$, E.A. Beljaev leg. 
MALE GENITALIA. The skeleton. Vinculum is massive, with large conic saccus, without internal modifications. Valva is elongate, connected with vinculum by two articulations: dorsal - formed by wide firm anterior process of lateral wall of the costa, and ventral - formed by short ventroanterior process of the sacculus. Costa short, with dorsal bulbous swelling near the end. Transtilla is belt-shaped, arched, with rounded dilation near the costa. Sacculus is large and strong, clasper as small falcate sclerite formed dorsoproximal corner of valvula. Clasper forms small but firm, prominent, falcate sclerite.

The musculature. Abductor and adductor of valva, $m 3(2)$ and $m 4$, are located at the ventral corner of tegumen, $m 3(2)$ is extending from its anterior rib just dorsad of $m 4$ and distally reaching for posterior rib of basal dilation of the transtilla, $m 4$ is extending from medial wall of the tegumen corner and attached to side of this dilation laterad to $m 3(2)$. Flexor of valvae $m 5(7)$ consists of 2 branches: stout medial intravalvar $m 5 a(7 a)$, lying from medial wall of sacculus to clasper, and thinner vancilum-valvar $m 5 b(7 b)$, stretching between median wall of vinculum near the articulation with sacculus to the clasper.

NOTE. Stekolnikov \& Kuznetzov (1982) described the male genitalia musculature of $C$. pusaria, but with missing of vinculum-valvar branch of muscle $m 5$ (7). So, only vinculum-valvar region is considered here.

\section{DISCUSSION}

The genera Synegia and Platycerota (as Crypsicometa) were included in the tribe Deveniliini based on male genitala skeleton, which structure suggests musculature pattern, similar to Devenilia. The examination of musculature mainly confirms this suppose. Both, Synegia and Platycerota, possess the $m 4$ very strong and extending from lateroventral portion of vinculum, which is unknown in other ennomines still. So, this character could be considered as probable synapomorphy of these genera. However, it is a single common derived character in the musculature. Muscles $m 1$ develop typically for ennomines, and only in Devenilia weakened in coordination with degeneration the tegminal sclerites. The abductors of valves $m 3(2)$ are located differently in all genera: in Synegia they primitive extending from dorsal portion of tegumen, in Platycerota they extending from ventral corners of tegumen (which also frequently occurs in different ennomines), and only on Devenilia they unique attached to dorsal corners of vinculum. Muscles m5(7) are intravalvar in Synegia and Platycerota, but in part juxta-valvar in Devenilia. Muscle $m 8(3), m 6(5)$ and $m 7(6)$ do not demonstrate any common specializations except their original development in Devenilia. The last genus has normal hemitranstillae, whereas in Synegia they are modified in finger-like process without attaching muscles, and in Platycerota they are totally reduced. In Synegia and Platycerota muscles $m 3(2)$ are unusually attached to membrane in the area of lacking portions of normal hemitranstilla, that could be considered as their synapomorphy. Distal attachment of $\mathrm{m} 4$ to ventromedial corner of costa also may be synapomorphy of Synegia and Platycerota, but quite different shape of $m 4$ apodeme in both genera suggests possibility of homoplasy. 
Generally, all three genera are highly diversificated morphologically. Nevertheless, Synegia and Platycerota could form a sister pair, considering their probable synapomorphies in the male genitalia. Based on the male genitalia skeleton, East Asian genera Hypulia Swinhoe, 1894; Nothomiza Warren, 1894; Yashmakia Warren, 1901; Parasynegia Warren, 1893; Eurychoria Prout, 1916; Bulonga Walker, 1859;

Borbacha Moore, 1887 (the male genitalia for all see Holloway, 1994); Heterostegania Warren, 1893 (see Stüning, 2000); Orthobrachia Warren, 1895 (see Huang et al., 2016); and Boninnadagara Inoue, 1994 (see Inoue, 1994) could be related to Synegia and Platycerota. They all share heavy developed vinculum and modifications of the hemitranstillae area, which supposes similar musculature structure. All these genera, excepting the Devenilia, the most authors currently associate with tribe Baptini (Holloway, 1994; Stüning, 2000; Huang et al., 2016).

However, the type genus of Baptini, Lomogtrapha, possesses different structure of the male genitalia skeleton and musculature. Thus, L. bimaculata possesses broad lobe-like valvae, simple narrow vinculum and common position of $m 3(2)$ and $m 4$ near ventral corner of tegumen and dorsal corner of vinculum. Actually, the enumerated genera demonstrate more similarity with Caberini, which typical members have superficially similar large vinculum and elongated valvae with tend to form different dorsal processes. However, the musculature is different: in the $C$. pusaria muscles $m 3(2)$ and $m 4$ both attached to the tegumen, which also is one of the typical arrangements in ennomines along with the state in L. bimaculata. Large saccus correlates with very large phallus, and there is a muscle extending from vinculum to valva, reminiscent the state in Synegia and Platycerota. But this muscle has different origin: it is attached to clasper, bur not to costa, and it is a lateral branch of flexor valvae $m 5(7)$. So, superficially similar musculature structure reaches by deferent manner.

As to Devenilia, it strongly differs from all Baptini and Caberini by presence of tremendous labides, somewhat similar to those in Lithinini, Odontoperini, Nacophorini and Epionini (= Hypochrosini). However, in all known cases, members of the mentioned tribes have normal attachment of valvar muscles $m 3(2)$ and $m 4$. From the genera considered here, Parasynegia, Eurychoria and Synegia imitaria (Walker, 1861) possess plow-shaped or knife-like labides, reminiscent those in Devenilia, however much smaller. Tremendous spinose labides of $P$. incertaria, evidently, is deep secondary modification, reminiscent those in some Ennomini (as in Ourapreyx clara Butler, 1880 and Ourapteryx claretta Holloway, 1982; see Inoue, 1985; Holloway, 1994). Generally, presence of horn-like labides should be considered as simplesiomorphy for large series of the Ennominae tribes (Beljaev, 2006). Position of $m 3(2)$ mediad to $m 4$ on hemitranstilla is characteristic also to Baptini and Caberini, but, probably, it is symplesiomorphic state for all ennomines. The attachment of part of the muscle $m 5$ (7) to the juxta is characteristic to Baptini, but in Synegia and Platycerota this state could be secondary lost in coordination with trend to the juxta narrowing in all putative related genera. 


\section{CONCLUSION}

Genus Devenilia combines the characters mosaic of Baptini and Caberini, but, evidently, mostly in symplesiomorphic state. Position of $m 4$ is a single, but, probably, robust synapomorphy, associated Devenilia with Synegia, Platycerota and other putative related genera (Hypulia, Nothomiza, Yashmakia, Parasynegia, Eurychoria, Bulonga, Borbacha, Heterostegania, Orthobrachia, Boninnadagara), at that Devenilia occupies basal position to rest genera. Also, all have shortened and somewhat bulbous sacculi of valvae correlating with short $m 5(7)$, and a trend to attenuation of tegumen and its appendages (uncus and gnathos), although the latter manner of modification is easily homoplastic throughout Ennominae. Thus, there is a reason to accept Deveniliini as separate lineage in the Baptini - Caberini tribal complex of Ennominae, possibly even basal in relation to both latter tribes, taking into account the presence of plesiomorphic horn-like labides in some genera and species.

The strong morphological deviation of the Devenilia from the rest of putative Deveniliini genera and the absence of "transient forms" do not completely exclude possibility of homoplasy in the position of $m 4$ muscles. Molecular data would clarify this hypothesis; however, none of the genera presented here has so far been included in the multigene molecular phylogenies of geometrid moth (such as Sihvonen et al., 2011; Brehm et al., 2019; Murillo-Ramos et al., 2019; and others).

\section{ACKNOWLEDGEMENTS}

The study has been supported by the Russian Foundation for Basic Research (grant No 18-04-00944).

\section{REFERENCES}

Beljaev, E.A. 1998. Morphology of the copulatory apparatus of Devenilia corearia and description of a new tribe Deveniliini (Lepidoptera, Geometridae, Ennominae). Zoologicheskii Zhural, 77(4): 438-443. [In Russian with English summary]

Beljaev, E.A. 2006. A morphological approach to the Ennominae phylogeny (Lepidoptera, Geometridae). Spixiana, 29(3): 215-216.

Beljaev, E.A. 2008. Phylogenetic relationships of the family and subfamilies of geometrid moths (Lepidoptera: Geometridae). Chteniya pamyati N.A. Kholodkovskogo [Lectures in Memorian of N.A. Kholodkovsky], 60. Zoological Institute RAS, St. Petersburg. 238 pp. [In Russian with English summary]

Beljaev, E.A. 2016. Fam. Geometridae - Pyadenitzi. P. 518-666. In: Lelej, A.S. \& Beljaev, E.A. (Eds). Annotated catalogue of the insects of Russian Far East. Vol. II. Lepidoptera. Dalnauka, Vladivostok. [In Russian]

Beljaev, E.A. \& Mironov, V.G. 2019. Geometridae. P. 235-281. In: Sinev, S.Yu. (Ed.) Catalogue of the Lepidoptera of Russia. Edition 2. Zoological Institute RAS, St. Petersburg. [In Russian]

Brehm, G., Murillo-Ramos, L., Sihvonen, P., Hausmann, A., Schmidt, B., Õunap, E., Moser, A., Mörtter, R., Bolt, D., Bodner, F., Lindt, A., Parra, L. \& Wahlberg, N. 2019. New World geometrid moths (Lepidoptera: Geometridae): Molecular phylogeny, biogeography, taxonomic updates and description of 11 new tribes. Arthropod Systematics \& Phylogeny, 77: 457-486. DOI: https://doi.org/10.26049/ASP77-3-2019-5 
Forbes, W.T.M. 1939. The muscles of the lepidopterous male genitalia. Annals of the Entomological Society of America, 39(1): 1-10.

Holloway, J. 1994. The moths of Borneo, part 11: Family Geometridae, subfamily Ennominae. Malayan Nature Journal, [1993], 47: 1-309.

Huang, G.-H., Su, Z.-Y. \& Stüning, D. 2016. Taxonomic notes on the genus Orthobrachia Warren, with description of a new species from China and Thailand (Lepidoptera, Geometridae). ZooKeys, 609: 121-137. DOI: https://doi.org/10.3897/zookeys.609.8288

Inoue, H. 1994. The Geometridae of the Ogasawara islands (Lepidoptera). Bulletin of Otsuma Women's University Home Economics, 30: 195-223.

Kuznetzov, V. I. \& Stekolnikov, A. A. 1973. Phylogenetic relationships in the family Tortricidae (Lepidoptera) treated on the base of study of functional morphology of genital apparatus. Trudy vsesouznogo entomologicheskogo obshchestyva, 56: 18-43. [In Russian]

Kuznetzov, V.I. \& Stekolnikov, A.A. 2001. New approaches to the system of Lepidoptera of the world fauna (based on abdominal functional morphology). Trudy Zoologicheskogo instituta Rossiiskoi Akademii Nauk, St. Petersburg, 282: 1-462. [In Russian with English summary]

Murillo-Ramos, L., Brehm, G., Sihvonen, P., Hausmann, A., Holm, S., Ghanavi, H., Õunap, E., Truuverk, A., Staude, H.S., Friedrich, E., Tammaru, T. \& Wahlberg, N. 2019. A comprehensive molecular phylogeny of Geometridae (Lepidoptera) with a focus on enigmatic small subfamilies. PeerJ, 7: e7386. DOI: https://doi.org/10.7717/peerj.7386

Sihvonen, P., Mutanen, M., Kaila, L., Brehm, G., Hausmann, A. \& Staude, H.S. 2011. Comprehensive molecular sampling yields a robust phylogeny for geometrid moths (Lepidoptera: Geometridae). PLoS One, 6: e20356. DOI: https://doi.org/10.1371/journal.pone. 0020356

Speidel, W., Fänger, H. \& Naumann, C. M. 1996. The phylogeny of the Noctuidae (Lepidoptera). Systematic Entomology, 21(3): 219-251.

Stekolnikov, A. A. \& Kuznetzov, V.I. 1982. Functional morphology of the male genitalia and arrangement of new tribes of the geometrid moths, subfamily Ennominae (Lepidoptera, Geometridae). Entomologitsheskoe Obozrenie 61(2): 344-374. [In Russian]

Stüning, D. 2000. Additional notes on the Ennominae of Nepal, with descriptions of eight new species (Geometridae). Tinea 16 (Supplement 1): 94-152, + pls. 170-172.

Viidalepp, J. 1996. Checklist of the Geometridae (Lepidoptera) of the former U.S.S.R. Apollo Books, Stenstrup. $111 \mathrm{pp}$ 